\title{
Quality of life of women with locally advanced or metastatic breast cancer
}

\author{
Qualidade de vida de mulheres acometidas por câncer de \\ mama localmente avançado ou metastático
}

Calidad de vida de mujeres con cáncer de mama localmente avanzado o metastásico

\author{
Eunice de Oliveira Lacerda Lima $a^{a, b}$ \\ Marcelle Miranda da Silva ${ }^{a}$
}

\section{How to cite this article:}

Lima EOL, Silva MM. Quality of life of women with locally advanced or metastatic breast cancer. Rev Gaúcha Enferm. 2020;41:e20190292. doi: https://doi. org/10.1590/1983-1447.2020.20190292
Universidade Federal do Rio de Janeiro, Escola de Enfermagem Anna Nery, Rio de Janeiro, Rio de Janeiro, Brazil.

b Instituto Nacional de Câncer José Alencar Gomes da Silva (INCA), Hospital do Câncer III, Rio de Janeiro, Rio de Janeiro, Brazil.

\section{ABSTRACT}

Objectives: To identify the main affected domains of quality of life of hospitalized women with locally advanced or metastatic breast cancer; and to analyze the association between the level of quality of life and stage of cancer.

Method: This was a cross-sectional quantitative, study conducted in Rio de Janeiro, Brazil, between March and July 2017. Interviews were performed with 199 women. The researchers administered the European Organization for Research and Treatment of Cancer Quality of Life Questionnaire Core 30, with analysis using the Statistical Package for the Social Sciences software and the KruskalWallis test.

Results: Mean global health status was 32.04. On the functional scales, cognitive functioning scored the highest (60.47), while role functioning scored the lowest (12.48). Fatigue presented the highest mean (69.57). The scores for global health status and the functional scales (with the exception of the social functioning) decreased as staging progressed.

Conclusion: The stage of cancer affects the quality of life of the studied sample of women.

Keywords: Breast neoplasms. Quality of life. Palliative care. Health profile.

\section{RESUMO}

Objetivos: Identificar os principais domínios de qualidade de vida afetados em mulheres com câncer de mama localmente avançado ou metastático hospitalizadas; e analisar a associação entre o nível de qualidade de vida e o estadiamento do câncer.

Método: Estudo transversal, quantitativo, realizado no Rio de Janeiro, Brasil, entre março e julho de 2017. Entrevistaram-se 199 mulheres. Aplicou-se o European Organization for Research and Treatment of Cancer Quality of Life Questionnarie Core 30, com análise no Statistical Package for the Social Sciences e teste Kruskal-Wallis.

Resultados: A média do status de saúde global foi 32,04. Na escala funcional, o funcionamento cognitivo teve maior média $(60,47)$ e 0 desempenho pessoal a menor média (12,48). A fadiga apresentou maior média (69,57). 0 status de saúde global e a escala funcional (exceto social) reduziram seus escores à medida que 0 estadiamento avançava.

Conclusão: 0 estadiamento do câncer interferiu na qualidade de vida dessas mulheres.

Palavras-chave: Neoplasias da mama. Qualidade de vida. Cuidados paliativos. Perfil de saúde.

\section{RESUMEN}

Objetivos: Identificar los dominios de calidad de vida afectados en mujeres hospitalizadas con cáncer de mama localmente avanzado o metastásico; analizar la asociación entre el nivel de calidad de vida y la estadificación del cáncer.

Método: Estudio cuantitativo transversal realizado en Río de Janeiro, entre marzo y julio de 2017. 199 mujeres fueron entrevistadas. Se aplicó el European Organization for Research and Treatment of Cancer Quality of Life Questionnarie Core 30, para análisis el Statistical Package for the Social Sciences y la prueba Kruskal-Wallis.

Resultados: El estado de salud global promedio fue 32.04. El funcionamiento cognitivo tuvo el promedio más alto (60.47) y el desempeño personal más bajo (12.48). Fatiga presentó el promedio más alto (69.57). El estado de salud global y la escala funcional (excepto social) redujeron sus puntajes a medida que avanzaba la estadificación.

Conclusión: La estadificación del cáncer interfirió con la calidad de vida de estas mujeres.

Palabras clave: Neoplasias de la mama. Calidad de vida. Cuidados paliativos. Perfil de salud. 


\section{口INTRODUCTION}

According to the World Health Organization (WHO), quality of life (QoL) is defined as an individual's perception of themselves, of their position in life in the context of the culture and value systems in which they live and in relation to their goals, expectations, standards and concerns ${ }^{(1)}$. This is subjective information, but quantitative studies have worked on the concept to understand the relationships/associations between external and internal factors and individuals'lower or higher QoL $L^{(2-4)}$. In light of this concept, breast cancer affects the QoL of women in all areas of their lives.

When dealing with the variables relative to the stage of the disease and its treatment, studies have shown a negative impact on the QoL of women in more advanced stages of breast cancer, who manifest physical symptoms, especially gastrointestinal and/or psychosocial ones, even if undergoing anti-cancer treatments or when the care is palliative ${ }^{(2,5)}$.

The clinical staging of women with breast cancer is based on clinical history and evaluation, imaging tests and biopsies, varying according to the TNM staging system ( $T$ = tumor, $\mathrm{N}=$ degree of spread to regional lymph nodes and $M=$ metastasis); histological type of tumor; degree of differentiation (grade I - well-differentiated carcinoma; grade II - moderately-differentiated; grade III - poorly-differentiated); and the expression of hormone receptors: Human Epidermal Growth Factor Receiver-2 (HER2), estrogen and progesterone. The earliest staging is 0 (carcinoma in situ - Tis) and the most advanced is IV, while the other stages (I, II and III), with their subdivisions, depend on many different combinations of these factors ${ }^{(6)}$.

Locally advanced breast cancer is when the tumor mass at the time of diagnosis is large $(>5 \mathrm{~cm})$, or is of any size but has invaded adjacent structures and/or lymph nodes, i.e., already at clinical stage IIB. Because this entails other body parts being affected by the cells in the primary breast tumor, it is considered metastatic breast cancer (Stage IV). Thus, stage IV is characterized by the presence of metastasis (M1), independent of the other factors ${ }^{(7)}$.

How breast cancer affects the QoL of women is related to how the disease manifests itself and its treatments, including chemotherapy, radiotherapy, surgery and hormone therapy, which may cause and/or exacerbate side effects and psychosocial disorders. Depending on the treatment implemented and the stage of the disease, the QoL of women may be affected by pain, nausea, vomiting, fatigue, insomnia, hair loss, lymphedema, depression, mutilation, presence of wounds, fear of death, and others ${ }^{(8)}$.
To deliver comprehensive and humanitarian care, it is important to provide scientifically based techniques to evaluate these women's QoL, thus guiding the development of healthy behaviors, resilience and adjustment to the disease.

The study was guided by the following research question: Does cancer staging affect the QoL of women with locally advanced or metastatic breast cancer?

The aim was to identify the main health-related QoL domains affected in hospitalized women with locally advanced or metastatic breast cancer and to analyze the association between QoL level and cancer staging in this population.

\section{METHOD}

This was a cross-sectional quantitative study extracted from a Master's dissertation ${ }^{(9)}$ carried out in a High Complexity Oncology Reference Center in the city of Rio de Janeiro, Brazil. The center has five units with different specialties. The study was carried out in the unit specialized in treating and controlling breast cancer, in the clinical inpatient sector, which contains 26 beds distributed among seven wards.

The study population consisted of women with breast cancer hospitalized in these wards between March and July 2017, for a total of 289 patients. After applying the inclusion and exclusion criteria that were gathered based on the patients' health charts, all the eligible women were interviewed (199 women). This number was higher than the sample of 180 women that resulted from the ANOVA test, which was based on the estimated population of 383 hospitalized women in the second semester of 2016.

The inclusion criteria were women 18 years old or older, with locally advanced breast cancer, i.e., in clinical stages IIB and III (A, B and C), because of the greater capacity to develop metastases, and with proven metastasis, i.e., in stage IV.

The following exclusion criteria were applied:: women who presented mental confusion or prostration and cognitive impairment affecting reading and comprehension capacities; whose primary tumor was not in the breast; with any limiting factor, in pain, after three attempts of interviewing during the data collection period; who did not have their medical charts at the time of the interview or who were submitted to initial treatment outside of the referred institution. Mental confusion and cognitive impairment were assessed by reading the patients' charts and consulting members of the healthcare staff.

Of the 90 patients who did not participate in the survey, $74 \%$ presented mental confusion or prostration; $9 \%$ refused to participate; $6 \%$ whose primary tumor was not in the 
breast; $4 \%$ were in stage I (A and B) or IIA of the disease, who despite evolution is little likely, in general, presented a high histological degree, with the absence of hormonal receptors; $4 \%$ were submitted to initial treatment in another institution, and $2 \%$ did not have their patient chart.

Interviews were conducted by administering the European Organization for Research and Treatment of Cancer Quality of Life Questionnaire Core 30 (EORTC QLQ-C30), version 3.0, validated in Brazil ${ }^{(10)}$. This is the most used health-related QoL instrument in research, with good validity, reproducibility and comprehension scores ${ }^{(5,10)}$.

The supplementary module for evaluating QoL in breast cancer patients (EORTC-BR23) was not used in this study, because due to the clinical conditions of women during hospitalization, as well as the dynamics and routines of the setting itself, the time of the interviews had to be managed and focus on the general aspects contemplated in the functions of the EORTC QLQ-C30 questionnaire. It is noteworthy that the specificity of the EORTC-BR23 focuses on issues related to body image and sexuality.

The EORTC QLQ-C30 questionnaire was produced by EORTC, originally in English, and was translated into Brazilian Portuguese by the institution itself. The EORTC website provides the questionnaire free of charge for academic purposes. It contains 30 items and was designed to be multidimensional and to evaluate health-related QoL. It is divided into three dimensions: functional scales (physical, role, emotional, cognitive and social performance), symptom scales (fatigue, nausea and vomiting, pain, dyspnea, insomnia, appetite loss, constipation, diarrhea and financial difficulty) and general QoL. The functional and symptom scales are answered on a Likert scale, as follows: 1 - not at all, 2 - a little, 3 - quite a bit and 4 - very much. The general QoL scale is assessed from 1 (very poor) to 7 (excellent).

The interviews were carried out in a separate, private, noise-free room, or in the wards themselves, depending on the woman's preference and mobility condition. The woman could choose whether she wanted the presence of her companion during the interview.

The data were coded and analyzed with the help of the Statistical Package for the Social Sciences (SPSS), version 24. The EORTC QLQ-C30 was scored according to the rules established in the EORTC manual, ranging from 0 to 100, where low scores indicate lower QoL and higher scores suggest better QoL for the functional and general QoL scales. High scores for the symptom scales represent a high level of symptomatology and consequently, QoL.

The analysis of the results resulted in the main areas of QoL affected. To compare the three populations in each stage (II, III and IV), hypothesis tests were proposed for more than two populations, in which values of $p<0.05$ (established significance level) were considered significant.

The Shapiro-Wilk test was performed to verify the assumption of normality of data that would allow the use of parametric tests, in addition to graphical analysis using histograms. However, the assumption of normality was rejected after all the scales of the questionnaire were assessed. Thus, a non-parametric approach had to be chosen.

The Kruskal-Wallis test was carried out to assess the guiding question about whether the stage of cancer affected the women's QoL. An extension of this test was used to discover which of these populations had functions with different distributions, the Kruskal-Wallis multiple comparisons test.

The present study abided by the ethical principles of research with human beings, in accordance with Resolution no. 466/2012 of the Brazilian National Health Council. The study was approved by the Research Ethics Committee of the proposing and co-participating institutions in March 2017, with the respective presentation certificates for ethical appraisal: 63765417.5 .0000 .5238 and 63765417.5.3001.5274. The participants signed Free and Informed Consent Forms and the questionnaires were not identified.

\section{RESULTS}

The results of the EORTC QLQ-C30 questionnaire are shown in Table 1. The mean score for global health status was 32.04, with a standard deviation of 20.87, thus presenting a higher concentration of results in the lower half of the scale's score. The maximum value was 91.67 , indicating that none of the women presented the maximum score for QoL on the scale.

On analyzing the functional scales, the domain with the highest mean was cognitive functioning (60.47), which also presented the highest standard deviation (33.43), indicating a greater dispersion of results. Moreover, the role (12.48) and physical (27.67) domains scored the lowest on the functional scales, suggesting that they were the most affected functions. The standard deviation of the role functioning scale was the lowest (22.14), indicating greater concentration around the mean.

Considering the symptom scales, higher mean values were observed for fatigue (69.57), financial difficulties (69.01) and pain (67.42). However, financial difficulties presented the highest standard deviation (38.85).

Dyspnea (42.38), insomnia (47.40), and appetite loss (53.10) showed high standard deviations, indicating that 
although some scales obtained lower means, some women were affected considerably by such symptoms.

In all areas of the functional and symptom scales, there were scores in the minimum (0.00) and maximum (100.00) extremities.

After analyzing the distribution of data regarding the main QoL domains affected in this population, the researchers investigated how these values were distributed in relation to the current stages of the disease. Of the 199 women interviewed, 145 were currently in stage IV, while 31 women were currently in stage III, and 23, stage II.

As observed in Chart 1, the mean score of global health status decreased as the stages progressed, with the following means: stage II - 41.30, stage III - 36.02, and stage IV - 29.71.

In terms of the functional scales, cognitive and social functioning scored the highest in all stages of the disease.

Table 1 - Descriptive statistics of the EORTC QLQ-C30 questionnaire Rio de Janeiro RJ, Brazil, 2017

Scales Min. Median Mean $\begin{gathered}\text { Standard } \text { Meviation Max. } \\ \text { D. M }\end{gathered}$

\section{Global health status}

Global health status

\section{Functional scales}

Physical functioning

Role functioning

Emotional functioning

Cognitive functioning

Social functioning

\section{Symptom scales}

Fatigue

0.00

0.00

0.00

0.00

0.00

0.00

0.00

0.00

0.00

Financial difficulties

0.00

0.00

0.00

0.00

0.00

0.00

Dyspnea

Insomnia

Appetite loss

Constipation

Diarrhea
50.00

77.78

69.57

25.95

100.00

33.33

34.00

33.70

100.00

83.33

67.42

35.35

100.00

33.33

42.38

41.26

100.00

33.33

47.40

43.72

100.00

66.67

53.10

39.92

100.00

33.33

47.57

42.82

100.00

0.00

8.21

24.27

100.00

Source: research data, 2017 


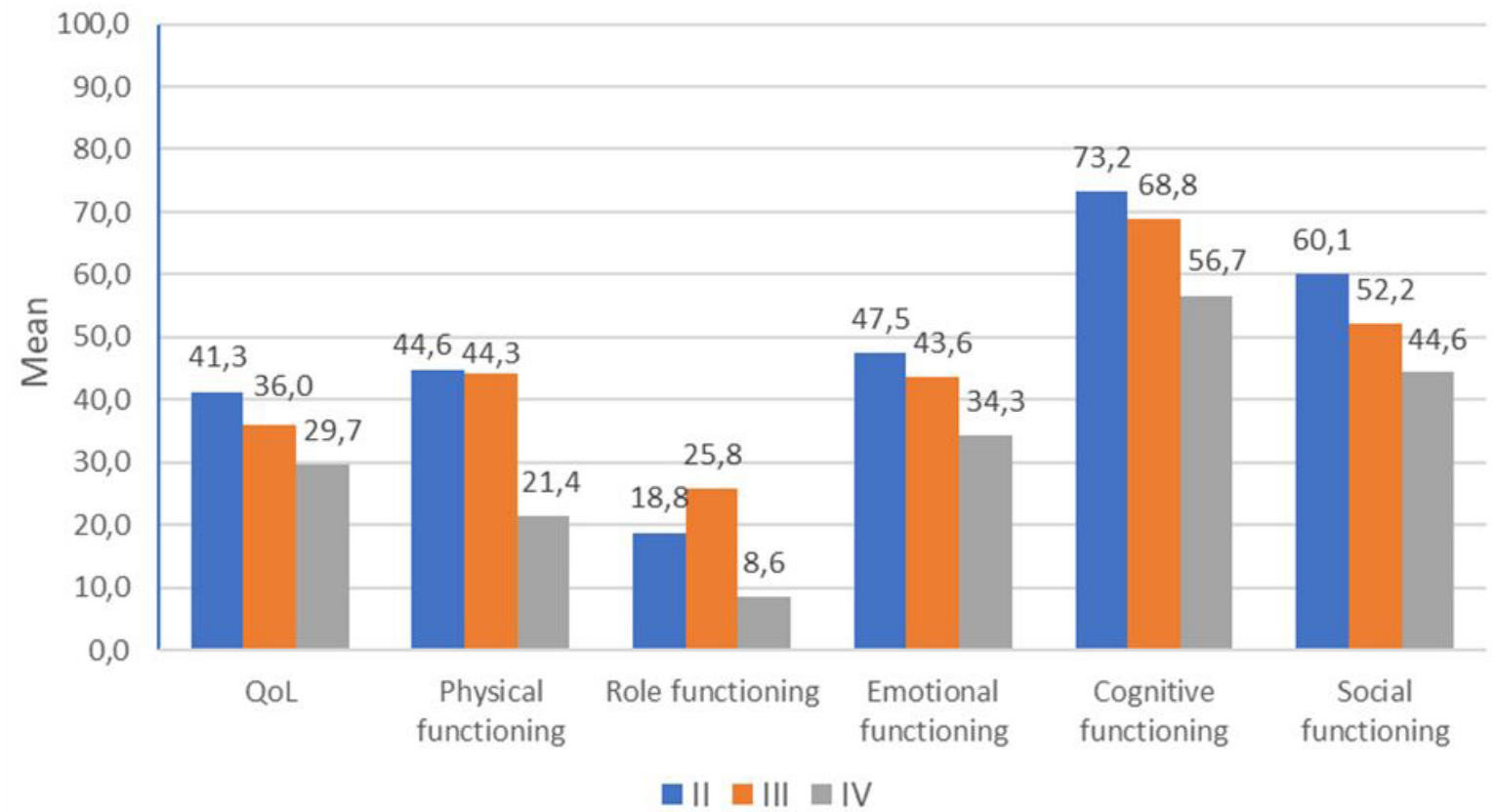

Graph 1 - Results of global health status and functional scales by the current stage of the disease. Rio de Janeiro, RJ, Brazil, 2017 Source: Research data, 2017.

QoL: Global health status.

Even though these domains presented higher scores when compared to the other domains of the functional scales, their scores also decreased as the stages of the disease advanced.

In contrast, the role functioning domain obtained the lowest scores in all stages of the disease. However, it should be noted that stage III presented a higher score than the others, displaying a different trend than the other domains of the functional scales.

To understand this finding, a more in-depth analysis of role functioning was performed, observing each woman's individual score for this domain. One possible reason for this domain not following the trend of the others, i.e., decreasing as stages increased, was the presence of outliers, for three women in stage III presented high scores (100, 83.3 and 83.3).

To verify this hypothesis, the researchers carried out the same analysis associating the current stage of the disease with role functioning without these three women. However, the domain still followed a different trend, i.e., the mean score of the role functioning scales in stage III was still higher than that of stage II (Graph 2).

In relation to the symptom scales, the three domains with the highest means were fatigue, financial difficulty and pain. The order of these dimensions varied according to the stage of the disease. In stage II and IV, the highest means were, respectively fatigue, financial difficulty and pain; while in staging III, the highest means were financial difficulty, pain and fatigue (Graph 3).
The association between the health-related QoL level and the interference of cancer staging in this population can be seen in Graphs 1 and 3, as well as in Table 2. There is worsening of the QoL and functional scales, in addition to an increase in the symptomatology of women with the most advanced current stage of the disease.

Table 2 shows the Kruskal-Wallis test results for the null hypothesis that all populations have equal distribution functions against the alternative hypothesis that at least two

\section{Role functioning 28 women in stage III}

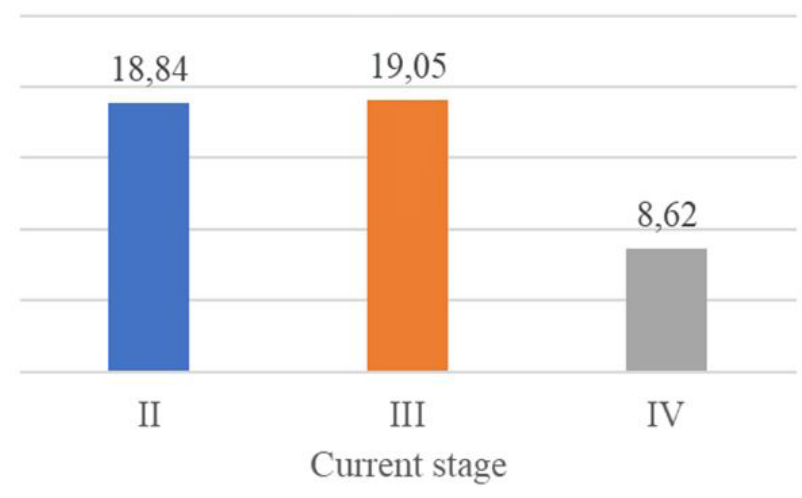

Graph 2 - Role functioning of the 28 women in stage III. Rio de Janeiro, RJ, Brazil, 2017 Source: Research data, 2017 
of the populations have different distribution functions. Significance was set at $p<a=0.05$.

There was statistical evidence to reject the hypothesis that the global health status did not differ according to the stage of the disease. On the functional scales, the null hypothesis was rejected for almost all domains, except for social functioning. However, it is clear that both its medians and the $25 \%$ and $75 \%$ interquartile intervals decreased with the progression of the stages of the disease.

Last, the symptom scales showed a higher a p-value than the established level of significance; therefore it was not statistically significant enough to affirm that the stage of disease was a factor that influences its domains.

\section{DISCUSSION}

Regarding global health status of the 199 women, the mean was 32.04 and median, 33.33. Some women presented score 0 , however, the maximum was 91.67 , showing that none of the women presented the maximum score of health-related QoL; and its domains presented varied intensity ${ }^{(4)}$.

In Germany, a study assessing the QoL of women with metastatic breast cancer submitted to palliative chemotherapy on an outpatient basis found an average global health status of $56 \cdot 4^{(11)}$. A similar result was found in another study conducted in Germany that compared the QoL of patients with breast cancer with no progression and with progression; the results showed that the global health status of women with progression was lower (52.2), compared with $56.8^{(2)}$.

The context of these studies, often related to the health profile of women and the socioeconomic, cultural and general environmental differences between Brazil and Germany, can influence the divergence in scores for global health status, because in Germany, the results were significantly higher than those in the present study. Furthermore, statistics indicate higher rates of breast cancer mortality in developing countries, such as Brazil, pointing to factors such as late diagnosis, deficiencies in defining prognostic factors, and poorer QoL during the course of the disease ${ }^{(3)}$.

Results indicate that, during hospital stays, many women's global health status worsens because of different indications, which in clinical practice are related to the exacerbation of signs and symptoms relative to the disease's progression and/or the toxicity of the therapy received. Patients with metastasis, who represented most of the sample in this study,

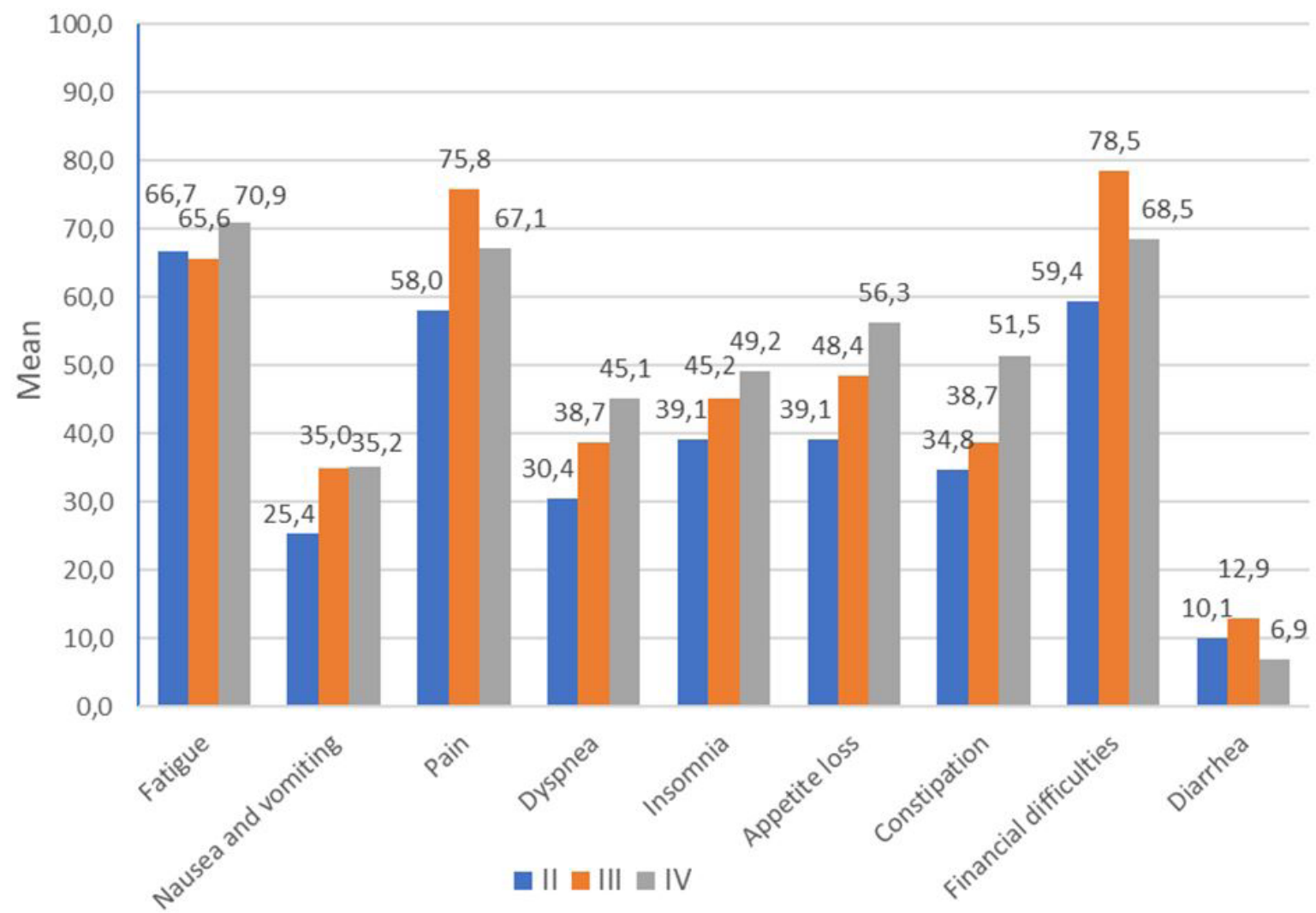

Chart 3 - Results of the symptom scale by current stage of the disease. Rio de Janeiro, RJ, Brazil, 2017 Source: Research data, 2017 
Table 2 -Medians of the EORTC QLQ-C30 questionnaire scales separated by current stage of the disease. Rio de Janeiro, RJ, Brazil, 2017

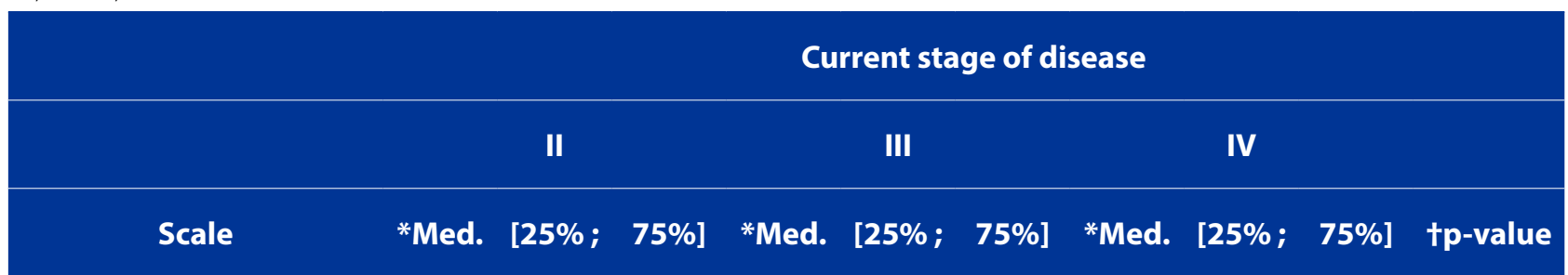

\section{Global health status}

Global health status

41.67

\section{Functional scales}

Physical functioning

Role functioning

0

33.33

Emotional functioning

$58.33 \quad 29.17-70.83$

41.67

16.67

$83.33 \quad 50 \quad 100$

83.33

33.33100

66.67

33.33

83.3

0.0248

Social functioning

$50 \quad 41.67$

83.33

50

$33.33 \quad 83.33$

50

\section{Symptom scales}

\begin{tabular}{|c|c|c|c|c|c|c|c|c|c|c|}
\hline Fatigue & 77.78 & 50 & 88.89 & 66.67 & 44.44 & 88.89 & 77.78 & 55.56 & 88.89 & 0.5057 \\
\hline Nausea and vomiting & 16.67 & 0 & 50 & 33.33 & 0 & 66.67 & 33.33 & 0 & 50 & 0.5451 \\
\hline Pain & 83.33 & 8.33 & 83.33 & 83.33 & 66.67 & 100 & 83.33 & 50 & 100 & 0.1906 \\
\hline Dyspnea & 0 & 0 & 66.67 & 33.33 & 0 & 66.67 & 33.33 & 0 & 100 & 0.2074 \\
\hline Insomnia & 0 & 0 & 83.33 & 33.33 & 0 & 100 & 33.33 & 0 & 100 & 0.5116 \\
\hline Appetite loss & 33.33 & 0 & 83.33 & 33.33 & 16.67 & 83.33 & 66.67 & 33.33 & 100 & 0.1324 \\
\hline Constipation & 0 & 0 & 83.33 & 33.33 & 0 & 66.67 & 66.67 & 0 & 100 & 0.0824 \\
\hline Diarrhea & 0 & 0 & 0 & 0 & 0 & 0 & 0 & 0 & 0 & 0.3066 \\
\hline Financial difficulties & 66.67 & 33.33 & 100 & 100 & 66.67 & 100 & 100 & 33.33 & 100 & 0.2050 \\
\hline
\end{tabular}

Source: Research data, 2017

${ }^{*}$ Med. Median; † Kruskal-Wallis test, with significance level set at $p<a=0.05$ 
manifest symptoms such as fatigue, nausea and vomiting, dyspnea, and appetite loss much more intensely, which negatively impact their $\mathrm{QoL}^{(2)}$.

A study carried out in the Northeast of Brazil obtained a global health status of 76.14; however, $43.4 \%$ of the women of their sample had not been submitted to any treatment other than neoadjuvant chemotherapy. In that study, most of the women were not bedridden and did not need help in activities of daily living; furthermore, their physical condition and treatment did not interfere in their family life ${ }^{(12)}$.

Thus, hospitalized women with advanced breast cancer are more debilitated. The present study showed that cancer staging interfered in the QoL of these women, and the mean general health status presented the following behavior according to the current stage of the disease: stage $\|=41.30$; stage $\mathrm{II}=36.02$; and stage $\mathrm{IV}=29.71$.

Thus, advanced disease negatively impacted health-related QoL. More advanced stages of breast cancer at the time of diagnosis coupled with compromised role, physical and emotional functioning have been associated with greater likelihood of worse QoL ${ }^{(3)}$.

Cognitive function presented higher mean value (60.47), which represents a preserved memory and concentration capacity for leisure activities. Role functioning was the most compromised domain, with the lowest mean value (12.48). Emotional functioning obtained the third highest score (37.7). It is worth noting that $74.37 \%$ of the women had been in the hospital up to five days at the time of the interview, and the questions were related to their perception about their emotional state, whether nervous or depressed, which can be enhanced due to their recent hospitalization.

Although emotional functioning scored low, it addresses issues that are often neglected, either by the woman's self-report or by the health team when designing conducts, and this may reflect in the lower QoL score ${ }^{(3)}$.

Role (12.48) and physical (27.67) functioning were the most compromised domains. Role functioning was evaluated based on daily and work activities, as well as hobbies or leisure. The women's perception about performing these activities may be related to the limitations imposed by the hospital context, and above all, by the reason for hospitalization.

Occupation is an important strategy for maintaining QoL because of its close relationship with role functioning ${ }^{(13)}$. Considering that $72.86 \%$ of the women were currently in stage IV, the therapeutic objectives must be realigned in order to contribute to the women's perceived QoL, ranging from the intensification of palliative care to increasing the possibilities of carrying out activities of daily living with autonomy and dignity, receiving comprehensive integral care, either at home or as inpatients, and thus promoting $\mathrm{QoL}^{(4)}$.
Regarding the functional scales, the Kruskal-Wallis test compared the three stages of the disease and showed statistical evidence to state that the physical, role, emotional and cognitive functioning scales presented a significant difference with a $p$-value $<a=0.05$, as the disease advanced.

Regarding the symptom scales of the 199 women, the scales with the three highest scores were fatigue (69.57), financial difficulty (69.01) and pain (67.42). The symptom with the lowest mean score was diarrhea (8.21); however, some individuals scored 100 for this symptom.

Fatigue is an important symptom related to cancer that interferes with QoL, as shown in another study in which it was the highest-scoring symptom (51.9) $)^{(11)}$. In terms of the relationship between QoL and cancer-related fatigue, higher levels of fatigue are associated with lower overall QoL ${ }^{(12,14)}$.

Fatigue is a multifactorial and subjective symptom, involving not only biological factors, but also cognitive and psychological aspects. It is the most frequent symptom in women with breast cancer; however, little is known about its mechanisms $s^{(4,14-16)}$.

On analyzing fatigue separately, it was the symptom with the highest mean score among women in stage IV (70.88). Studies point to a close relationship between fatigue and worse QoL, mainly because of greater dependence on other people for daily care, discouragement, and weakness ${ }^{(4)}$.

Nausea and vomiting both scored 34.0. This can be explained by the side effects of the treatments performed, the advanced stage of the disease and the metabolic changes it causes, in addition to the hospitalization process itself, which results in a change of diet. These symptoms affect physical well-being and further increase feeling of weakness ${ }^{(5)}$.

The dimension that obtained the second highest mean score was financial difficulties (69.01). The financial condition of patients can be affected by the complex treatment process and managing all the issues that may arise over the course of the disease, such as symptoms, side effects, and the need for hospitalization. Although the present data were collected in a public health institution that provides free care, poor financial conditions can interfere in obtaining the necessary support for improving $\mathrm{QoL}^{(3)}$.

Pain obtained the third highest mean score (67.2) on the symptom scales. However, it is necessary to consider the magnitude of this score, which is in line with references that address the importance of pain among cancer patients ${ }^{(4-5)}$.

Uncontrolled pain can affect the QoL of women. Efficient pain management is essential, whether through pharmacological or non-pharmacological treatment, to attempt to improve QoL. The perception and intensity of pain may affect multiple spheres inherent to humans, and thus it is necessary to treat it from the "total pain" perspective ${ }^{(11)}$. 
The data demonstrate that pain at stage III (75.8) was greater than at stage IV (67.1). In clinical practice, opioid use is common, especially in patients at stage IV, which can result in better pain control. However, it is noteworthy that this symptom obtained a high score in all of the stages.

When analyzing the symptom scales in relation to the stages of the disease, the p-value was higher than the established level of significance, therefore not high enough to affirm that the stage of the disease influences the symptom scales.

\section{a CONCLUSION}

Global health status presented an average score of 32.04 , with a maximum of 91.67, indicating that none of the 199 women obtained the maximum score on the health-related QoL scale. The functional scale domains that presented higher and lower average were, respectively, cognitive functioning (60.47) and role functioning (12.48). In the symptom scales, fatigue scored the highest mean (69.57) and diarrhea, the lowest (8.21).

When comparing QoL results with stages II, III and IV, statistically significant differences were found with global health status, the functional scales, (with the exception of the social functioning), because their scores decreased as the stage of disease advanced. In conclusion, cancer staging interfered with the health-related QoL of women with locally advanced breast cancer, especially those with metastases.

The results provide practical implications for improving the QoL of women with advanced or metastatic breast cancer. Considering that nursing and health care planning is based on knowledge about the main affected areas of QoL, nurses can direct actions to promote factors that improve QoL in addition to preventing, avoiding or minimizing negative factors. The correlation between poorer QoL and the most advanced stages of the disease presents the challenge of ensuring palliative care. Results with better QoL in chronic diseases can reduce health costs.

It is of great social importance to analyze the QoL of these women and the impact that this disease and its treatment have on their lives. Women and their families are weakened by and more sensitive because of the disease, and thus actions are needed to help them in the adjustment to improve and maintain QoL.

A limitation of this study includes the fact that it was conducted in a single setting, which is exclusively covered by the Brazilian Unified Health System. It is also important to consider the differences between social, demographic and cultural aspects in Brazil and in the world when considering the replication of results. However, the results of this sample were in line with data from national and international literature.

\section{REFERENCES}

1. World Health Organization (CH). WHOQOL Measuring quality of life. Geneva: WHO; 1997 [cited 2018 Jan 12]. Available from: https://www.who.int/ mental_health/media/68.pdf

2. Müller V, Nabieva N, Häberle L, Taran FA, Hartkopf AD, Volz B, et al. Impact of disease progression on health-related quality of life in patients with metastatic breast cancer in the PRAEGNANT breast cancer registry. Breast. 2018;37:154-60. doi: https://doi.org/10.1016/j.breast.2017.08.008

3. Edib Z, Kumarasamy V, Abdullah NB, Rizal AM, Al-Dubai SAR. Most prevalent unmet supportive care needs and quality of life of breast cancer patients in a tertiary hospital in Malaysia. Health Qual Life Outcomes. 2016;14:26. doi: https://doi.org/10.1186/s12955-016-0428-4

4. Freire MEM, Sawada NO, França ISX, Costa SFG, Oliveira CDB. Health-related quality of life among patients with advanced cancer: an integrative review. Rev Esc Enferm USP. 2014;48(2):357-67. doi: https://doi.org/10.1590/S00806234201400002000022

5. Sawada NO, Nicolussi AC, Paula JM, Caro MPG, Garcia CM, Quintana FC. Quality of life of Brazilian and Spanish cancer patients undergoing chemotherapy: an integrative literature review. Rev Latino-Am Enfermagem. 2016;24:e2688. doi: https://doi.org/10.1590/1518-8345.0564.2688

6. American Joint Committee on Cancer. AJCC Cancer Staging Manual. Chicago: American College of Surgeons; 2018 [cited 2019 Nov 10]. Available from: https://cancerstaging.org/references-tools/deskreferences/Documents/ AJCC\%20Cancer\%20Staging\%20Form\%20Supplement.pdf

7. Simos D, Clemons M, Ginsburg OM, Jacobs C. Definition and consequences of locally advanced breast cancer. Curr Opin Support Palliat Care. 2014;2018];8(1):33-8. doi: https://doi.0rg/10.1097/SPC.0000000000000020

8. Çömez A, Karayurt 0 . We as spouses have experienced a real disaster!: a qualitative study of women with breast cancer and their spouses. Cancer Nurs. 2016;39(5):E19-E28. doi: https://doi.org/10.1097/NCC.0000000000000306

9. Lima EOL. Qualidade de vida de mulheres acometidas por câncer de mama localmente avançado ou metastático [dissertação]. Rio de Janeiro (RJ): Universidade Federal do Rio de Janeiro; 2018 [cited 2019 Nov 10]. Available from: http://objdig.ufrj.br/51/teses/870115.pdf

10. Michels FA, Latorre MR, Maciel MS. Validity, reliability and understanding of the EORTC-C30 and EORTC-BR23, quality of life questionnaires specific for breast cancer. Rev Bras Epidemiol. 2013 [cited 2017 Nov 11];16(2):352-63. doi: https://doi.org/10.1590/S1415-790X2013000200011

11. Puetzler J, Feldmann Jr. RE, Brascher AK, Gerhardt A, Benrath J. Improvements in health-related quality of life by comprehensive cancer pain therapy: a pilot study with breast cancer outpatients under palliative chemotherapy. Oncol Res Treat. 2014;37(9):456-62. doi: https://doi.org/10.1159/000365537

12. Lôbo SA, Fernandes AFC, Almeida PC, Carvalho CML, Sawada NO. Quality of life in women with breast cancer undergoing chemotherapy. Acta Paul Enferm. 2014 ;27(6):554-9. doi: https://doi.org/10.1590/1982-0194201400090

13. Brekke MF, la Cour K, Brandt Å, Peoples H, Wæhrens EE. The association between ADL ability and quality of life among people with advanced cancer. Occup Ther Int. 2019:2629673. doi: https://doi.org/10.1155/2019/2629673 
14. Fabi A, Falcicchio C, Giannarelli D, Maggi G, Cognetti F, Pugliese P. The course of cancer related fatigue up to ten years in early breast cancer patients: what impact in clinical practice? Breast. 2017;34:44-52. doi: https://doi.org/10.1016/j. breast.2017.04.012

15. Canário AC, Cabral PU, Paiva LC, Florencio GL, Spyrides MH, Gonçalves AK. Physical activity, fatigue and quality of life in breast cancer patients. Rev Assoc Med Bras. 2016;62(1):38-44. doi: https://doi.org/10.1590/1806-9282.62.01.38
16. Chan RJ, Yates P, McCarthy AL. The development and preliminary testing of an instrument for assessing fatigue self-management outcomes in patients with advanced cancer. Cancer Nurs. 2017;40(1):48-57. doi: https://doi.org/10.1097/ NCC.0000000000000347

\section{- Corresponding author:}

Marcelle Miranda da Silva

E-mail: marcellemsufrj@gmail.com

Associate editor:

Helga Gouveia

Editor-in-chief:

Maria da Graça Oliveira Crossetti 